\title{
Determination of the Effects of Hydrothermal Alteration on Silicate Stardust with Secondary Ion Mass Spectrometry and Transmission Electron Microscopy
}

\author{
Rhonda M. Stroud ${ }^{1}$, Bradley De Gregorio ${ }^{2}$, Jemma Davidson ${ }^{3}$, Larry Nittler ${ }^{3}$ and Conel M. O’D. \\ Alexander ${ }^{3}$ \\ 1. Materials Science and Technology Division, Naval Research Laboratory, Washington, DC 20375 \\ 2. Nova Research, Inc., Alexandria, VA 22308 \\ 3. Department of Terrestrial Magnetism, Carnegie Institution of Washington, Washington, DC \\ 20015
}

Interplanetary dust particles and the matrices of primitive meteorites (chondrites) preserve dust that condensed around a generation of stars that were older than the Sun [1]. However, the fraction of stardust preserved varies significantly for different meteorites. For example, optical microscopy suggests that both the CO chondrite Dominion Range (DOM) 08006 and the ungrouped carbonaceous chondrite Northwest Africa (NWA) 5958 appear to have highly unequilibrated matrix mineralogies, yet secondary ion mass spectrometry (SIMS) studies show that the fine-grained matrix of DOM contains $>$ $200 \mathrm{ppm}$ of O-rich presolar grains [2], whereas that of NWA contains only $50 \mathrm{ppm}$ [3]. It is generally believed that the same populations of stardust were delivered to the asteroidal parent bodies of all chondrites, so the differences in stardust grain populations are generally attributed to hydrothermal alteration and/or thermal metamorphism in the parent asteroids, or weathering of the meteorites on Earth. Through coordinated SIMS and transmission electron microscopy (TEM) measurements, we seek to determine the properties of the stardust grain population incorporated into the Solar System, the properties of the grains that survive asteroidal processing, and by deduction, the missing population of grains in more altered meteorites that is now indistinguishable from materials that formed in the Solar System.

We identified 101 preserved oxygen-rich (silicate + oxide) stardust grains in a polished thin section of DOM, and 21 grains in a thin section of NWA, by SIMS measurement of the grains' oxygen isotope compositions, with the Cameca NanoSIMS 50L at the Carnegie Institution of Washington (CIW). Figure 1 shows the distribution of oxygen isotope compositions of the DOM and NWA grains, in comparison with those of previously reported grains. The DOM grain population includes more ${ }^{18} \mathrm{O}-$ depleted grains than does the NWA population. This difference may simply reflect the lower number of NWA grains analyzed. On the other hand, if this difference is real it could reflect selective grain survival due to a difference in the properties (e.g., elemental composition, crystal structure, or grain size) among grains that originated in different stars.

Cross-sections for TEM analysis of surviving grains from each meteorite were prepared by focused ion beam (FIB) lift-out methods with the Nova 600 FIB-SEM at the Naval Research Laboratory (NRL). The subsequent TEM analyses were performed at NRL with a JEOL 2200FS scanning transmission electron microscope, equipped with a Noran System Six energy dispersive spectrometer. A total of five grains from DOM and two grains from NWA have been analyzed to date (Table 1).

Comparison of the matrix of DOM and NWA at the TEM scale, shows that the DOM matrix consists primarily of sub-micron anhydrous silicate grains, nanoscale metal and sulfide grains, and abundant amorphous material, whereas the NWA matrix contains abundant phyllosilicates, partially equilibrated 
metal and sulfides, and silicate grains with iron-rich rims. The preserved presolar grains in DOM include a complex, concentrically zoned grain with crystalline silicates and oxide phases, two olivine grains, and two amorphous grains with non-stoichiometric compositions. The preserved grains in NWA include an enstatite whisker and a polycrystalline spinel grain. The enstatite grain amorphized under the electron beam during attempts at lattice imaging. The higher than expected beam sensitivity likely reflects incipient hydrous alteration.

Although the total number of grains analyzed so far is too small to draw statistically significant conclusions about the grain populations from the two meteorites, there are clear differences. The hydrothermal alteration of the matrix of NWA was sufficient to partially alter nanocrystalline silicates, although oxides are preserved. The partial alteration of the enstatite grain, and lack of abundant glassy material in the matrix, suggests that the majority of amorphous or poly-nanocrystalline silicate stardust was destroyed in this meteorite. In contrast, DOM preserves single-crystal, poly-nanocrystalline, and amorphous grains. With some simplifying assumptions, we can use these data to provide a testable estimate of the well-crystallized: amorphous ratio of presolar silicates incorporated into the early Solar System. Based on the two NWA grains, we estimate the crystalline silicate: oxide ratio at 1:1. Typical estimates from SIMS and Auger electron spectroscopy of the total silicate to oxide ratio in the most primitive meteorites are $\sim 20: 1$ or higher [4]. This gives the destroyed weakly crystalline or amorphous fraction at 19 parts in 20, or the well-crystallized: amorphous ratio of $<1: 19$, e.g. $<5 \%$. Additional TEM studies of O-rich presolar grains in pristine and hydrothermally altered meteorites are needed to confirm this prediction.

\section{References}

[1] A. Davis, Proc. Nat. Acad. Sci, 108, 19142-19147 (2011).

[2] L. Nittler et al, Lunar and Planet. Sci. Conf. Proc., Abstract \#1719 (2013).

[3] L. Nittler et al. Meteor. \& Planet. Sci, Abstract \#5233 (2012).

[4] J. Leitner et al., Astrophys. J., 745:38 (2012).

Table 1. Summary of presolar grain data.

\begin{tabular}{|c|c|c|c|}
\hline Grain & $\begin{array}{l}\delta^{17} \mathrm{O} \\
(\%)\end{array}$ & $\begin{array}{l}\delta^{18} \mathrm{O} \\
(\%)\end{array}$ & $\begin{array}{l}\text { Composition and } \\
\text { Structure }\end{array}$ \\
\hline $\begin{array}{l}\text { NWA } \\
\text { e1-5 }\end{array}$ & $\begin{array}{l}+796 \\
\pm 102\end{array}$ & $\begin{array}{l}-1 \\
\pm 36\end{array}$ & $\begin{array}{l}\mathrm{MgSiO}_{3} \\
\text { enstatite, amorphized in TEM }\end{array}$ \\
\hline $\begin{array}{l}\text { NWA } \\
\text { e2-15 }\end{array}$ & $\begin{array}{l}+628 \\
\pm 70\end{array}$ & $\begin{array}{l}-12 \\
\pm 23\end{array}$ & $\begin{array}{l}\mathrm{Mg}_{0.97} \mathrm{Cr}_{0.11} \mathrm{Al}_{1.91} \mathrm{O}_{4} \\
\text { Polycrystalline spinel }\end{array}$ \\
\hline $\begin{array}{l}\text { DOM } \\
\text { A2C-15 }\end{array}$ & $\begin{array}{l}+1290 \\
\pm 44\end{array}$ & $\begin{array}{l}-15 \\
\pm 12\end{array}$ & $\begin{array}{l}\mathrm{Mg}_{1.66} \mathrm{Fe}_{0.33} \mathrm{Ni}_{0.03} \mathrm{Al}_{0.02} \mathrm{Si}_{1.00} \mathrm{O}_{4} \\
\text { olivine (tentative) }\end{array}$ \\
\hline $\begin{array}{l}\text { DOM } \\
\text { A2C2- } \\
25 \mathrm{a}\end{array}$ & $\begin{array}{l}5034 \\
\pm 145\end{array}$ & $\begin{array}{l}13 \\
\pm 25\end{array}$ & $\begin{array}{l}\mathrm{Mg}_{0.33} \mathrm{Fe}_{0.86} \mathrm{Ca}_{0.03} \mathrm{Al}_{0.06} \mathrm{Si}_{0.84} \mathrm{O}_{3} \\
\text { amorphous }\end{array}$ \\
\hline $\begin{array}{l}\text { DOM } \\
\text { A2C2- } \\
25 \mathrm{~b}\end{array}$ & $\begin{array}{l}+763 \\
\pm 54\end{array}$ & $\begin{array}{l}-334 \\
\pm 17\end{array}$ & $\begin{array}{l}\mathrm{Mg}_{1.85} \mathrm{Fe}_{0.14} \mathrm{Ni}_{0.01} \mathrm{Si}_{1.00} \mathrm{O}_{4} \\
\text { olivine }\end{array}$ \\
\hline $\begin{array}{l}\text { DOM } \\
\text { A2-18 }\end{array}$ & $\begin{array}{l}+1554 \\
\pm 45\end{array}$ & $\begin{array}{l}-87 \\
\pm 11\end{array}$ & $\begin{array}{l}\mathrm{Mg}_{0.45} \mathrm{Fe}_{0.74} \mathrm{Ni}_{0.07} \mathrm{Ca}_{0.03} \mathrm{Al}_{0.05} \mathrm{Si}_{0.82} \mathrm{O}_{3} \\
\text { amorphous }\end{array}$ \\
\hline $\begin{array}{l}\text { DOM } \\
\text { A3-CN1 }\end{array}$ & 570 & -370 & $\begin{array}{l}\mathrm{Mg}_{1.24} \mathrm{Fe}_{0.43} \mathrm{Ni}_{0.9} \mathrm{Ca}_{0.01} \mathrm{Al}_{0.02} \mathrm{Si}_{1.03} \mathrm{O}_{4} \\
\text { concentrically zoned, } \\
\text { polycrystalline olivine, Ca-rich } \\
\text { crystal, Al-rich oxide }\end{array}$ \\
\hline
\end{tabular}

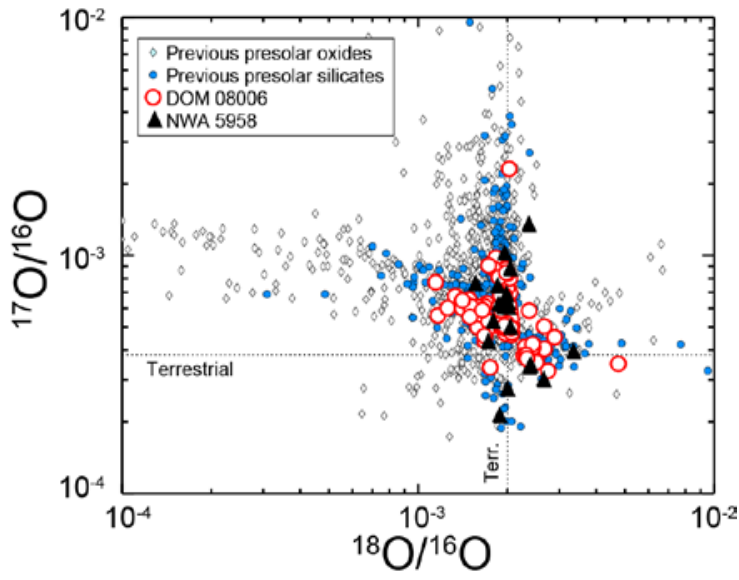

Figure 1. Comparison of the oxygen isotope compositions of O-rich presolar grains in DOM 08006, NWA 5958 with previously reported grains in other meteorites. 